\title{
Students' motivation in a disc golf-lesson and a soccer-lesson: An experimental study in the Physical Education setting
}

\author{
Kristian Vernegaard, Bjørn Tore Johansen and Tommy Haugen ${ }^{\star}$ \\ University of Agder, Kristiansand, Norway
}

\begin{abstract}
One of the purposes of physical education (PE) in both Norway and Denmark is that PE should inspire to a lifelong active lifestyle. Based on the self-determination theory, the aim of the present study was to compare students' intrinsic motivation, extrinsic motivation, and perceived competence in a lifestyle sport inspired PE-lesson (disc golf) to a traditional PE-lesson (soccer) and general PE. In addition, we aimed to investigate whether differences in motivation and perceived competence were conditional of the students' relative attitude toward PE. The result of the study revealed that perceived competence was higher in the disc golf-lesson compared to the soccerlesson and general PE. No overall differences in intrinsic motivation were found. However, when investigating differences in intrinsic motivation according to the students' relative attitude toward $\mathrm{PE}$, the results indicated that the students with a negative attitude toward PE was significantly more intrinsically motivated in disc golf-lesson compared to soccer-lesson and general PE. The findings may be seen as further recommendations to physical educators to vary the activity choices in physical education classes.
\end{abstract}

Keywords: Lifestyle sports; physical education; intrinsic motivation; extrinsic motivation; percieved competence, sports motivation

Received: November, 2016; Accepted: August, 2017; Published: September, 2017

\section{Introduction}

One of the purposes of physical education (PE) in both Norway and Denmark is that PE should inspire to a lifelong active lifestyle (Utdanningsdirektoratet, 2016; Ministeriet for Børn og Ligestilling, 2016) and the enhancement of young individuals' predispositions toward lifelong participation in sport and physical

${ }^{\star}$ Correspondence to: Tommy Haugen, Faculty of Health and Sport Sciences, University of Agder, Post Box 422, 4604 Kristiansand, Norway. Email: tommy.haugen@uia.no 
activity has typically been justified in terms of a taken-for-granted role of physical education in health promotion (Cale, 2000; Shephard \& Trudeau, 2010). When aiming at promoting a physically active lifestyle, PE seems a promising arena, because (almost) all children and youth are accessible in the school system (Sallis et al., 1992). Self-determination theory (Deci \& Ryan, 1985; Deci \& Ryan, 2000) is a framework of motivation that considers individuals to be actively seeking optimal challenges and new experiences to master and integrate. Deci and Ryan (1985) identified three types of motivation; intrinsic motivation, extrinsic motivation, and amotivation to account for the differing reasons why individuals engage in activities. Conditions supportive of individual's experience of autonomy, competence, and relatedness are argued to foster the most volitional and high quality forms of motivation (intrinsic motivation; Deci \& Ryan, 1985). Chatzisarantis, Biddle, and Meek (1997) revealed that the degree to which students are intrinsically motivated in PE acts as a predictor of leisure-time physical activity intentions and subsequent leisure time physical activity behavior. Students whose motivation is self-determined toward PE are more likely to be physically active in their spare time (Standage, Duda, \& Ntoumanis, 2003). Integrating the self-determination theory (Deci \& Ryan, 1985) in PE, a relationship between students' intention to remain physically active past graduation and intrinsic motivation was discovered (Moreno-Murcia, Huéscar, \& Cervelló, 2012; Stanley, Cumming, Standage, \& Duda, 2012; Standage et al., 2003). Moreover, Chatzisarantis and Hagger (2009) identified a positive relationship between autonomous motivation in a PE-setting and intention to be active in leisure time, while a study from Bagøien, Halvari and Nesheim (2010) also indicated that motivation in the PE-domain has the potential to be transformed into both intention and motivation in leisure time activity.

One of the factors used to determine the level of intrinsic motivation is perception of competence (Deci \& Ryan, 1985). Students are more likely to engage in activities they believe will lead to success, assuming society rewards achievements (Sonstroem, 1997). Previous research has connected adolescent's physical activity intentions and behavior to perceived physical competence (Biddle \& Armstrong, 1992; Biddle \& Goudas, 1996; Kimiecik, Horn, \& Shurin, 1996). Wang and Biddle (2001) have also linked perceived physical competence to intrinsic motivation in adolescents, showing that the most intrinsically motivated adolescents possessed more positive perceptions of their own physical competence. Weiss and Duncan (1992) showed that peer acceptance in youth sport was highly and positively related to levels of physical competence. Those who perceive a lack of physical competence usually find PE meaningless and are only involved because it is mandatory or because of fear of punishment (Ntoumanis, 2001).

To find an activity in the PE-setting that all the students are equally satisfied with may seem difficult, because students are equipped with different preferences and interests, backgrounds, and skillsets (Graham, 2008). Green, Smith, and Roberts 


\section{K. Vernegaard et al.}

(2005) described sport and team games as the heart of physical educational curriculum and classified soccer as a "traditional" game, with 32 per cent of young people in England and Wales aged 11 - 16 participating in football frequently. Adolescents usually report dissatisfaction with the overrepresentation of a small number of sports in schools and express desire to experience a wider choice of activities (MacPhail, Kirk, \& Eley, 2003). This is consistent with the findings of Green et al. (2005) who stated that soccer has become less popular, in participatory terms, since the early 1990's. Weiss (2000) stated that by matching the activity to the child (and not the child to the activity), and by including so-called "lifestyle sports" in the physical education curriculum, the reductions of experts are assumed to lead to more equalized levels of competence. However, a study from Norway showed that adolescents involved in organized competitive youth sports outside school reported more positive attitudes towards PE and scored higher on self-determined motivation for PE compared to those who were not (Säfvenbom, Haugen, \& Bulie, 2015). The study argues that PE in Norway seems to favor students who are involved in competitive youth sports, because a lot of the PE-content coincides with the logic of competitive youth sports.

The form of "alternative" sports (as a contrast to "ordinary", "traditional", or "conventional" sports), such as lifestyle sports (Wheaton, 2010), are equally diverse and different as sports in general. Lifestyle sports includes a wide range of activities and the common denominator seems to be that it does not fit under the Western "achievement sport" (Eichberg, 1998) umbrella, and these activities are generally conceptualized as forms of play rather than sports (Howe, 2003). Lifestyle sports are usually regarded relatively loosely structured activities mostly controlled by the participants themselves, with free engagement-terms and flexible time schedules. According to Wheaton (2010), lifestyle sports are most often different to the competitive and masculinized western achievement sport cultures.

According to Thornton (2004), disc sports, such as Ultimate and Disc Golf, are examples of lifestyle sports. Thornton (2004) argues that the "Spirit of the Game" (World Flying Disc Federation, 2016) captures relevant components of lifestyle sports. By focusing on sportsmanship, fair play, mutual respect, and basic joy of the game, disc sports may represent an alternative to the traditional sports usually seen in PE (Green et al., 2005; MacPhail et al., 2003).

Based on the abovementioned reasoning, one may suggest that PE could benefit from including a wider range of activities beyond the traditional ones, because inclusion of activities with the ideology and practical framework of lifestyle sports may increase feelings of competence and intrinsic motivation (Deci \& Ryan, 2000; Featherstone, 1991), and possibly also reduce extrinsic motivation. Thus, the aim of the present study was to compare students' intrinsic motivation, extrinsic motivation, and perceived competence in a lifestyle sport PE-lesson (disc golf) to a traditional PE-lesson (soccer) and general PE. In addition, we aimed to investigate whether differences in motivation and perceived competence were conditional of the students' relative attitude toward $\mathrm{PE}$. 


\section{Hypotheses}

Based on the abovementioned arguments, the following hypotheses have been formulated:

A. Students will experience lower levels of extrinsic motivation and higher levels of intrinsic motivation and perceived physical competence in a disc golflesson (lifestyle sport) compared to a soccer-lesson (traditional activity) and general PE.

B. Students with the most negative attitude towards PE will experience a reduction in level of extrinsic motivation and an increase in level of intrinsic motivation and perceived competence from the soccer-lesson (traditional activity) to the disc golf-lesson (lifestyle sport), whereas students with the most positive attitude towards PE will not.

\section{Methods}

Students from four different schools (two Norwegian and two Danish) were offered to participate, resulting in a convenience sample of 637 students that all agreed to participate in the present study. Parental consent was obtained for participants younger than the age of 16 . The study was approved by the Norwegian social science data services - NSD. All the responses were anonymous and could not be traced back to individual students after the end of the study.

The study design is experimental, with a crossover design, indicating that all participants were exposed to the two experimental conditions (i.e., "Lifestyle Sports Lesson"; disc golf, and "Traditional Activity Lesson"; soccer). In addition, the participants completed a pen-and-paper survey assessing their attitude and motivation toward and in PE. The experiment and subsequent data collection took place at the different schools during regular PE-lessons. Thus, students who potentially did not agree to participate in the survey were still obligated to participate in the lessons, but only participants with a signed consent answered the survey (i.e., participated in the study). Only one (1) student did not agree to participate.

The project lasted for 3 weeks and was divided into 4 phases (figure 1). After the first phase (obtaining written consent), the second phase included a survey assessing their general motivation in and general attitudes toward PE. Phase 3, second week PE-lesson 1: The participants in each class were randomly divided into two groups - group A and group B (to counterbalance the experimental conditions). Group A received a lifestyle sport based PE-lesson, where the first author was responsible for teaching disc golf to the participants. The lesson included some short technical exercises (i.e., correct throwing techniques) in addition to disc golf play (6 baskets course, groups of 3-4 students). The lesson focused on aspects central in "the spirit of the game" (World Flying Disc Federation, 2016); sportsmanship, fair play, mutual respect, and basic joy of the game. At the same time, group B participated in a "traditional" PE-lesson (represented by soccer) lead by their regular teacher. At the 


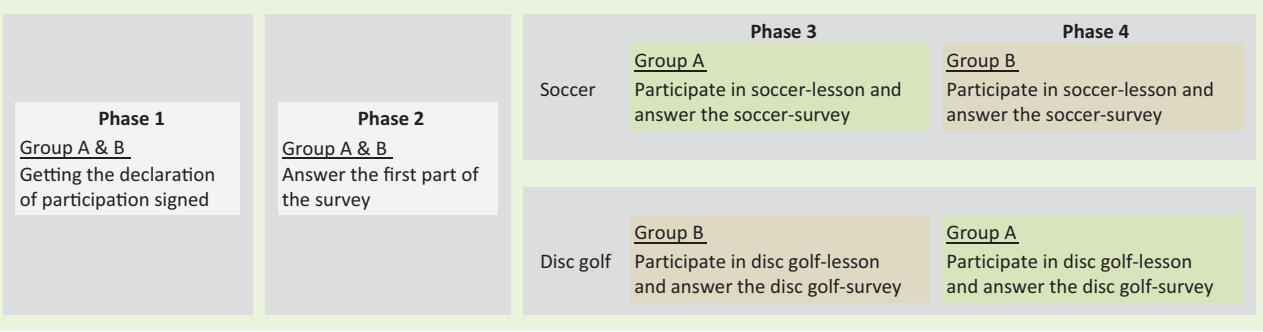

Figure 1. Illustration of study design.

end of the lesson, both groups met and both groups answered the survey adjusted according to their activity (group $\mathrm{A}-$ disc golf modified questions, group $\mathrm{B}-$ soccer modified questions). This part of the survey took 10-15 minutes. Phase 4, third week - PE-lesson II: Group A and B switched activity; group A had the soccer-lesson while group B had disc golf-lesson. At the end of the lesson, the groups repeated the survey from phase 3 (group A - soccer modified questions, group B - disc golf modified questions).

\section{Measurements}

Intrinsic and extrinsic motivation were measured using subscales from a simplified version (due to time constraints) of the Situational Intrinsic Motivational Scale SIMS (Guay, Vallerand, \& Blanchard, 2000). Item selection was based on the items with the highest factor loadings obtained in two previous studies of Norwegian adolescents (Erdvik, Øverby, \& Haugen, 2014; Säfvenbom et al., 2015). SIMS is originally developed by Guay et al. (2000), and has been shown to be a valid and reliable tool in many physical activity contexts (Standage et al. 2003). The SIMS-items (4 questions measuring intrinsic motivation and 3 questions measuring extrinsic motivation) used in the present study were based on the following stem: "Why do you participate in physical education?", and were measured on a 7-point Likert scale (Allen \& Seaman, 2007) ranging from (1) “does not correspond at all" to (7) "corresponds exactly". Higher scores indicate higher perceived motivation. The items were in phase 3 and 4 modified to correspond to the two experimental conditions (i.e., soccer and disc golf).

Perception of competence was measured using the sub-component "competence" from Basic Psychological Needs in Exercise Scale - BPNES (Vlachopoulos \& Michailidou, 2006). BPNES is a self-report measure designed to assess the extent to which the innate psychological need for autonomy, competence, and relatedness are fulfilled within a specific movement context (Vlachopoulos, 2008). Respondents are asked to report the extent of their agreement on a 5-point Likert scale ranging from (1) "do not agree at all" to (5) "very strongly agree" (Vlachopoulos, 2008). In the present study, the 5-point Likert scale was converted into a 7-point Likert scale ranging from (1) "do not agree at all" to (7) "very strongly agree". Russel and Bobko (1992) recommend the use of 7-point Likert-type scales over 5-point scales and 
Dawes (2008) argues that changing scale format does not necessarily destroy the comparability of historical data. The items were in phase 3 and 4 modified to correspond to the two experimental conditions (i.e., soccer and disc golf). The items used from SIMS and BPNES were converted into indexes, thus giving mean scores for intrinsic motivation, extrinsic motivation, and perceived competence.

Cronbach's alpha was used to determine the internal consistency of the simplified indexes. The Cronbach's alpha in this study ranged from 0.79 (lowest) to 0.95 (highest), which according to Cortina (1993) can be considered acceptable.

When investigating the general attitude toward PE, the students were asked to evaluate the phrase; "What do you think about PE classes?" on a (1) "I dislike PE very much" to (7) "I like PE very much" Likert scale. Based on the quartiles the sample was divided into three groups ("relatively negative attitude" (rNA): $<25^{\text {th }}$ percentile; "medium" (rMA): $25^{\text {th }}$ percentile $\leq \mathrm{x} \leq 75^{\text {th }}$ percentile; "relatively positive attitude" (rPA): $>75^{\text {th }}$ percentile) according to their relative general attitude toward PE.

\section{Statistical analyses}

Reliability analysis was conducted in SPSS to determine the Cronbach's alpha value on the simplified questionnaire to investigate the internal consistency of the instruments (Field, 2013). To examine changes in intrinsic motivation, extrinsic motivation, and perceived competence between general PE, soccer, and disc golf, repeated measures ANOVA tests were used (Field, 2013).

When analyzing hypothesis $\mathrm{B}$, the students were divided into three groups based on satisfaction with physical education and 3 (conditions) $\times 3$ (groups) factorial ANOVA tests were conducted to investigate both main effects and potential interaction-effect (Field, 2013). An effect size (eta squared) close to .02 is considered small, close to .13 is considered medium, and close to .26 is considered large (Field, 2013). P-values $<.05$ were considered statistically significant.

\section{Results}

In the present study 637 students from $5^{\text {th }}$ to $10^{\text {th }}$ grade participated. During the intervention, some participants did not complete each phase. The lowest participation rate was $74 \%$ and the highest was $89 \%$, giving a mean of approximately $82 \%$.

A summary of the demographic data is shown in table 1 . Of the 637 participants, 312 were boys. $41 \%$ of the participants were from $8^{\text {th }}$ grade, while the other were spread across $5^{\text {th }}, 7^{\text {th }}, 9^{\text {th }}$ and $10^{\text {th }}$ grade. The study was conducted in two countries, and 328 participants were from the Norwegian school system, with the remaining participants from the Danish school system. Students with diverse cultural background were included and 472 only spoke the "native tongue" (i.e., either Norwegian or Danish) at home and 80 spoke both the native tongue and a foreign language at home. Subsequently, the remaining 63 participants did not speak the native tongue at home. 
Table 1. Demographical characteristics of the study sample

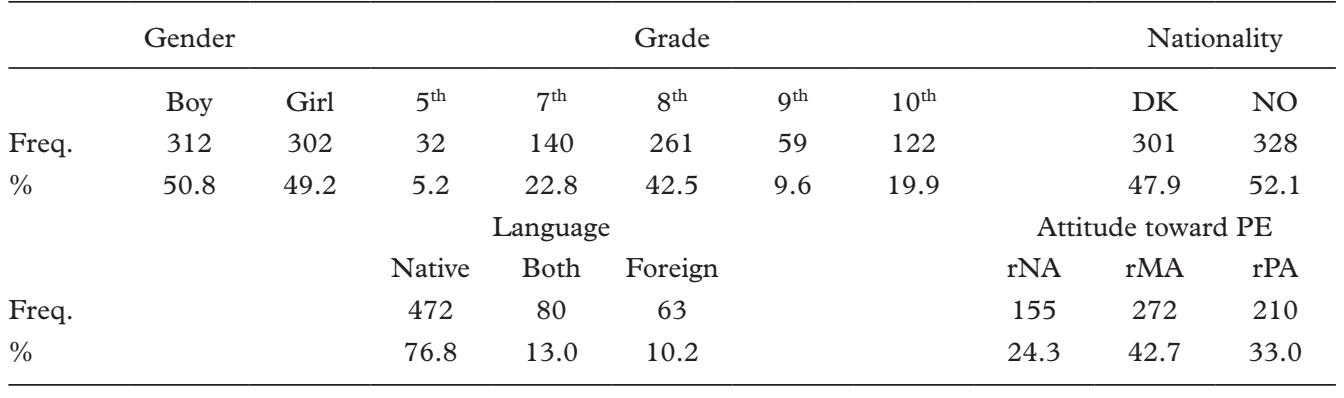

Note. $\mathrm{N}=637$. Sample size varies because of missing data. Freq $=$ frequency, DK = Denmark, NO = Norway, Both = both native and foreign. $\mathrm{rNA}=$ (Relatively) negative attitude toward PE; rMA = (Relatively) medium attitude toward PE; $\mathrm{rPA}=$ (Relatively) positive attitude toward PE.

Table 2. Level of Intrinsic Motivation, Extrinsic Motivation and Perceived Competence according to conditions

\begin{tabular}{lccc}
\hline & IM & EM & PC \\
\hline PE & $4.93(1.60)$ & $4.50(1.82)^{\mathrm{a}}$ & $5.23(1.44)^{\mathrm{b}}$ \\
SO & $4.87(1.92)$ & $4.27(1.92)^{\mathrm{a}}$ & $5.22(1.54)^{\mathrm{c}}$ \\
DG & $4.98(1.41)$ & $4.31(1.89)$ & $5.40(1.37)^{\mathrm{bc}}$ \\
\hline
\end{tabular}

Note: a - c equal letter indicates significant difference (repeated measures ANOVA, bonferroni corrected pairwise comparisons). Values are presented as mean (standard deviation). $\mathrm{PE}=$ general physical education; $\mathrm{SO}=$ soccer-lesson; $\mathrm{DG}=$ disc golf-lesson; $\mathrm{IM}=$ intrinsic motivation; $\mathrm{EM}=$ extrinsic motivation; $\mathrm{PC}=$ perceived competence.

In table 2, pairwise comparisons between general PE, traditional activity (soccer: $\mathrm{SO}$ ), and lifestyle sport (disc golf: DG) are presented. As can be seen, no significant differences in intrinsic motivation (IM) were found between SO, DG, or general $\mathrm{PE}$. There was however, a significant lower level of extrinsic motivation (EM) in SO compared to PE in general. EM in DG was not different from any of the other two contexts. Concerning perceived competence (PC), there was a significant difference between DG and the other two contexts.

As previously described in the methods-section, three mutually exclusive groups were made according to their relative attitude toward PE. Figure 2 portrays the difference in IM between general PE, SO, and DG conditional of relative attitude toward PE. The $3 \times 3$ factorial ANOVA indicated a statistically significant main effect, with a small effect size. Moreover, there was a statistically significant interaction effect with a moderate effect size (partial eta squared $=.12$ ). As can be seen, the rNA-group had a significant increase in IM from both PE to SO, and from SO to DG. Moreover, the rMA-group increased their IM from SO to DG. For the rPA-group however, there was a significant decrease in IM from general PE to SO and DG. All groups were statistically significant different from each other at all conditions, except for rMA og rNA in DG.

Regarding EM, the results are shown in figure 3. There was no significant main effect, nor any significant interaction effect. There was however, a statistical significant difference from $\mathrm{PE}$ to $\mathrm{SO}$ and $\mathrm{DG}$ for $\mathrm{rPA}$-group, indicating lower levels of $\mathrm{EM}$ in 


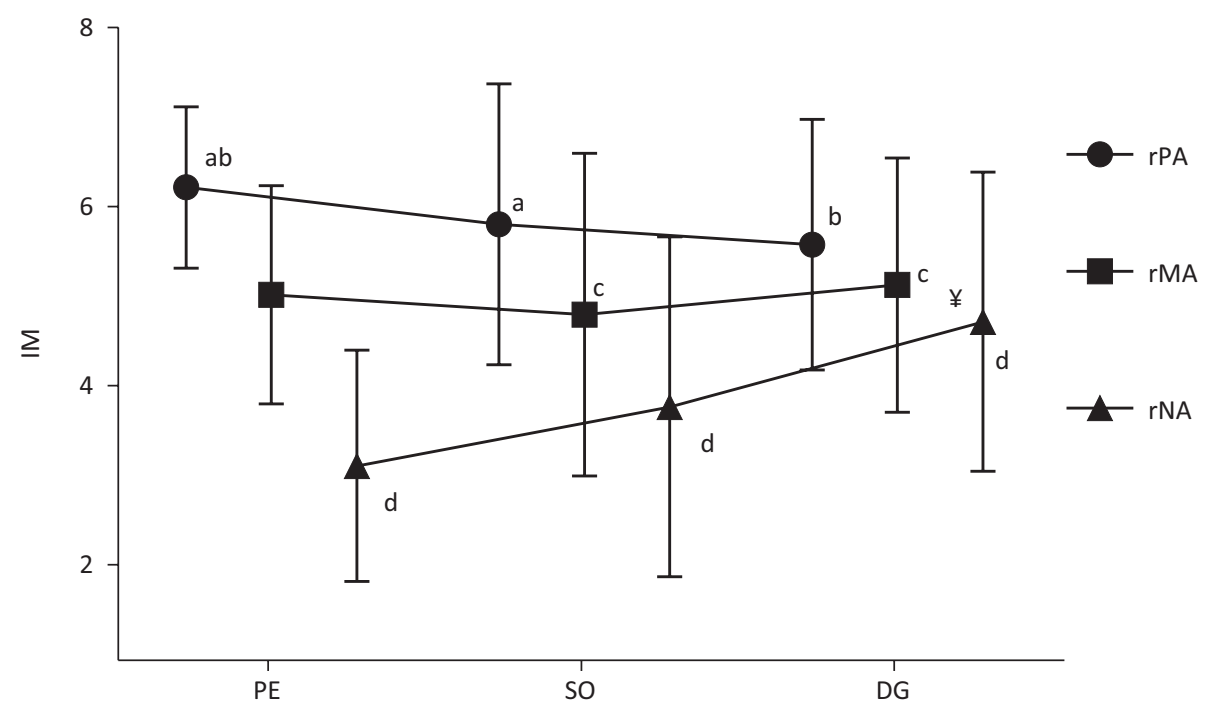

Figure 2. Differences in intrinsic motivation in general PE, Soccer-lesson, and Disc golf-lesson according to relative attitude toward PE.

Note: Data is presented as mean and standard deviations. IM = intrinsic motivation; $\mathrm{PE}=$ general physical education; $\mathrm{SO}=$ soccer-lesson; $\mathrm{DG}=$ disc golf-lesson; $\mathrm{rNA}=$ (Relatively) negative attitude toward PE; rMA = (Relatively) medium attitude toward PE; $\mathrm{rPA}=$ (Relatively) positive attitude toward PE. A $3 \times 3$ factorial ANOVA indicated significant main effect $(\mathrm{F}(2,453)=11.07, \mathrm{p}<.01$, partial eta-squared $=.05)$, and significant interaction effect $(F(4,908,=30.17, \mathrm{p}<.01$, partial eta squared $=.12){ }^{\text {a-d }}$ equal letter indicates significant (within-group) difference. Significant difference between all groups at all conditions except ${ }^{¥}$ (DG: rMA vs rNA).

SO and DG compared to general PE in the rPA-group. No difference between the three groups was found for EM, at any condition.

Figure 4 portrays the difference in PC between general PE, SO, and DG conditional of relative attitude toward PE. As can be seen, there was a statistically significant main effect, and an interaction effect. However, the effect size (eta-squared $=.03$ ) should be considered small. The only significant within-group differences observed was in the relatively negative attitude-group; PC in DG was higher than in general $\mathrm{PE}$ and SO. Between groups comparisons showed that all groups were different at all conditions, meaning that rPA-group had the highest levels of PC in all settings, whereas the rNA-group had the lowest levels of PC.

\section{Discussion}

The aim of the present study was to compare students' intrinsic motivation, extrinsic motivation, and perceived competence in a lifestyle sport PE-lesson (disc golf) with a traditional PE-lesson (soccer) and their general motivation in PE. In addition, we aimed to investigate whether differences in motivation and perceived competence were conditional of the students' relative attitude toward PE. 


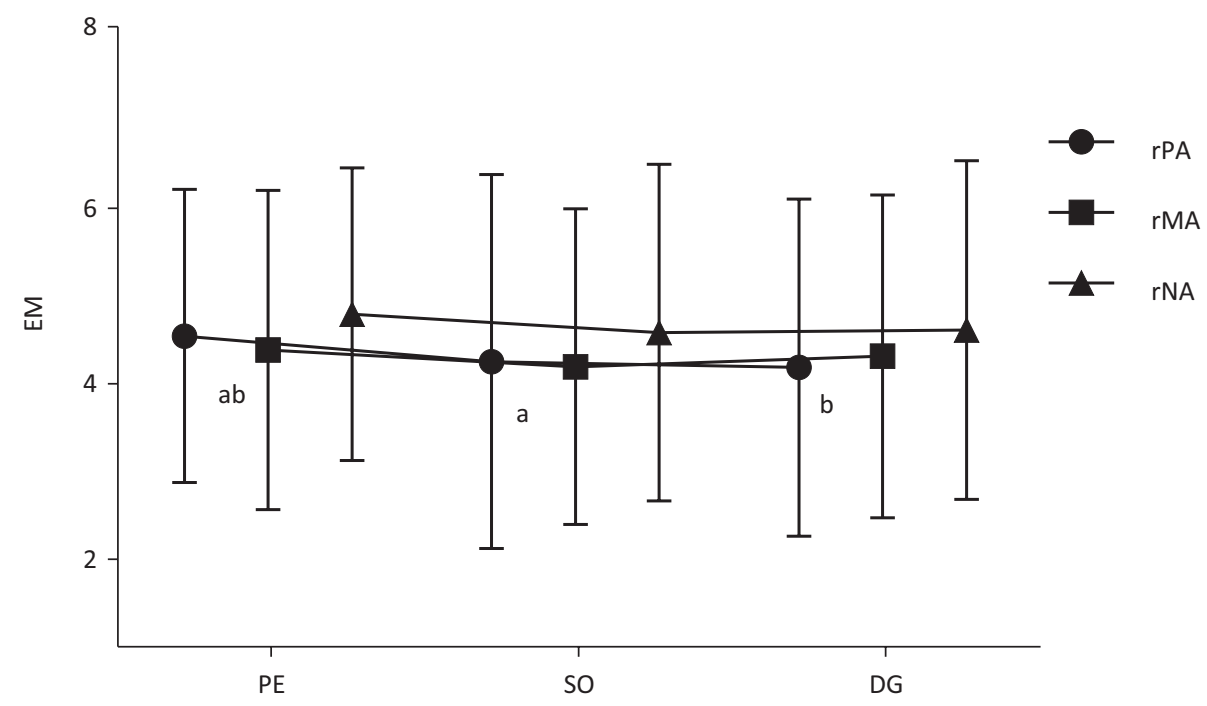

Figure 3. Differences in extrinsic motivation in general PE, Soccer-lesson, and Disc golf-lesson according to relative attitude toward PE.

Note: Data is presented as mean and standard deviations. $\mathrm{EM}=$ extrinsic motivation; $\mathrm{PE}=$ general physical education; $\mathrm{SO}=$ soccer-lesson; $\mathrm{DG}=$ disc golf-lesson; $\mathrm{rNA}=$ (Relatively) negative attitude toward PE; rMA = (Relatively) medium attitude toward PE; rPA = (Relatively) positive attitude toward PE. A $3 \times 3$ factorial ANOVA showed no significant main effect, and no significant interaction effect. $^{\mathrm{a}-\mathrm{b}}$ equal letter indicates statistical significant difference (within group comparison).

In the present study, the participants experienced a higher extrinsic motivation in soccer compared to general PE. This may indicate that students feel the most obligations toward their general physical education. Extrinsic motivation is the counterpart to intrinsic motivation, and refers to doing something because it leads to a separable outcome (Deci \& Ryan, 2000) and many of the tasks that educators want their students to perform may not be inherently interesting or enjoyable. Thus, knowing how to promote a more active volitional form of extrinsic motivation may become an important strategy for successful teaching (Deci \& Ryan, 2000). Students and people on a general basis engage in activities they believe will lead them to success, assuming society rewards achievements (Sonstroem, 1997). Being motivated by external motivation or external regulations are related to perceived lack of competence, and students who feel highly competent are less likely to be externally motivated in PE (Ntoumanis, 2001).

In the present study, the participants reported higher levels of perceived competence when engaging in disc golf compared with both soccer and their general PE. According to the self-determination theory, competence is one of the factors that increase self-determined motivation (Deci \& Ryan, 1985). Also, perceived physical competence has been connected to adolescent's physical activity intentions (Erdvik et al., 2014). The present study found that perceived competence was higher in the disc golf-lesson compared to the soccer-lesson and general PE for the students that 


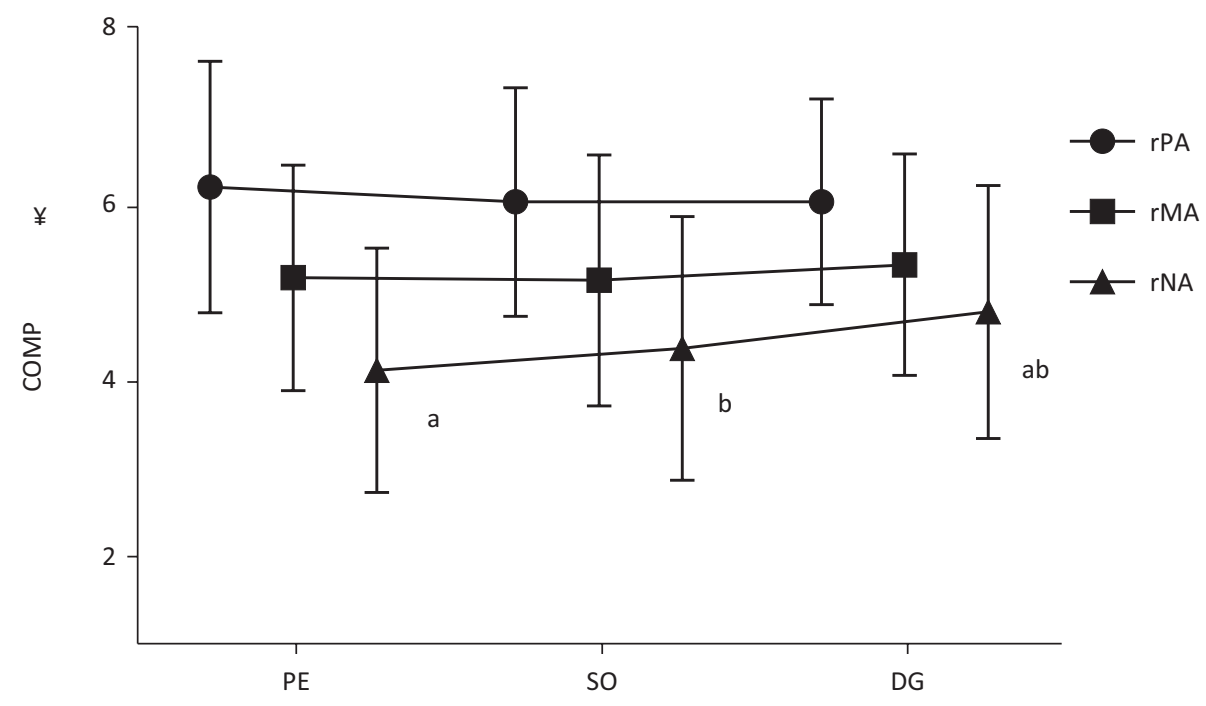

Figure 4. Differences in perceived competence in general PE, Soccer-lesson, and Disc golf-lesson according to relative attitude toward PE.

Note: Data is presented as mean and standard deviations. COMP = perceived competence; $\mathrm{PE}=$ general physical education; $\mathrm{SO}=$ soccer-lesson $; \mathrm{DG}=$ disc golf-lesson; $\mathrm{rNA}=$ (Relatively) negative attitude toward PE; rMA $=$ (Relatively) medium attitude toward PE; rPA $=$ (Relatively) positive attitude toward PE. A $3 \times 3$ factorial ANOVA showed a significant main effect $(\mathrm{F}(3,306)=$ $5.81 \mathrm{p}<.01$, partial eta-squared $=.04)$, and a significant interaction effect $(\mathrm{F}(4,614)=5.23$ $\mathrm{p}<.01$, partial eta-squared $=.03$ ). ${ }^{\mathrm{a}-\mathrm{b}}$ equal letter indicates statistical significant difference (within group-comparison). ${ }^{¥}$ Statistical significant difference between all groups at all conditions.

reported relatively negative attitudes toward PE. Weiss (2000) stated that physical educators should try to expose students to an optimal challenge by matching the activity to the students' level and not the student to the activity. Thus, one may argue that by implementing a lifestyle based activity in the physical education setting (such as disc golf), the individuals that normally do not collect the benefit of the subject (Säfvenbom et al., 2015) may increase their perceived competence and by that possibly engage more actively in the PE-lesson, because they believe they are skillful and see peer recognition within the reach (Weiss \& Duncan, 1992).

Lifestyle sports are often conceptualized as forms of play rather than sport (Howe, 2003), and the disc golf-lesson emphasized the mutual respect between players and the basic joy of play (World Flying Disc Federation on "Spirit of The Game"). Physical education provides ample opportunities for students to interact with other students - teammates and opponents (Ntoumanis, 2001). Physical education may contribute to the development of fundamental movement skills, physical competence, social skills, pro-social behavior, self-esteem, and pro-school attitude (Bailey, 2006). The potential of positive social relations in physical education settings may contribute to increased perceptions of relatedness, which is one of the factors important for self-determined motivation (Deci \& Ryan, 1985; 2000), and is described 


\section{K. Vernegaard et al.}

along with autonomy and competence as the innate psychological needs that underpin self-determined motivation (Deci \& Ryan, 1985; 2000).

Results revealed no significant differences in intrinsic motivation between general PE, disc golf-lesson, and soccer-lesson. This result did not confirm our pre-defined hypothesis (A). Bronfenbrenner (1979, p. 38) argues that: "To corrupt, somewhat, the classical terminology of experimental design, in ecological research, the principal main effects are likely to be interactions". Thus, the relationship between two variables may be conditional of the level of a third variable. This may seem as the case in the present study, because when investigating the differences in intrinsic motivation conditional of general attitude toward PE, the individuals with the relatively positive attitude toward PE actually reduced their intrinsic motivation from general PE to disc golf (and soccer). Whereas the individuals with relatively negative attitude toward PE increased their intrinsic motivation. One may argue, when implementing disc golf, the intrinsic motivation has been more leveled out, compared to the general PE and the soccer-lesson. In other words, disc golf may seem to "steal" intrinsic motivation from those most satisfied with PE as it is, and "give it" to those least satisfied with PE. This "stealing from the rich and giving to the poor" mechanism may be labeled a "Robin Hood effect". The findings in this study may indicate that there can be a potential within the PE context to improve the offer for students whose activity preferences may not coincide with that of Western achievement sport (Eichberg, 1998). It has been argued that the inclusion of sporting activities in PE may act as a double-edged sword (Säfvenbom et al., 2015) and that the quantity and quality of sport activities in PE should be considered with respect to the curricular objective of promoting a lifelong active lifestyle (Crum, 1993).

Pelletier, Fortier, Vallerand, and Briere (2001) argue that activities experienced as intrinsically rewarding are more likely to be performed again. In that context, activities that have the potential to increase intrinsic motivation among students that are generally low in self-determined motivation, is of relevance for both professionals and academics. Intrinsic motivation is associated with high quality learning and creativity (Deci \& Ryan, 2000). Thus it is important to identify factors that promote intrinsic motivation rather than undermine it. However, one should proceed with caution, because changing too much in PE may have detrimental effect on individuals that already are satisfied with the subject, and are already highly intrinsically motivated and are already fulfilling their need for competence. After all, a high number of students are pleased with the subject as it is (Säfvenbom et al., 2015).

Physical educators are bound by Norwegian (Utdanningsdirektoratet, 2012) and Danish (Ministeriet for Børn, Undervisning og Ligestilling, 2016) regulations to ensure that all students get adapted schooling. By implementing a lifestyle sport such as disc golf in PE, one may eliminate the majority of experts (when comparing with a traditional activity, in this case soccer), thus arrange for most students to seek and conquer optimal challenges (Deci \& Ryan, 1975). With variation in activity-choices and by implementing lifestyle sports in the PE setting one might be able to increase 
intrinsic motivation and perceived competence, and to promote a physically active lifestyle past graduation.

\section{Strengths and limitations}

Every study must consider its strengths and limitations, and one of the strengths of the present study is the number of respondents and the response rate. Moreover, strict crossover-experiments are scarce in the PE-literature. Thus, this study aim to complement other research methods assessed in research on PE.

However, the design of the present study also warrants some considerations. One may argue that the design sacrifices practical / clinical validity in the effort to maximize experimental control. Thus, the transferability into the context of PE may be considered limited. Moreover, the short-term nature of the intervention assessment indicates that situational motivation may change as a result of manipulation. However, potential long-term effects on contextual or global levels of students' motivation are still unknown. Future studies with longer intervention-periods and -follow-ups are warranted.

The role of lifestyle sports should be critically reviewed in future studies. The emphasized "spirit of the game" in the disc-golf session may also be transferred into more traditional sports (such as soccer). Future studies would do well to also investigate the effect of explicit focus on sportsmanship, fair play, mutual respect, and basic joy of the game in traditional PE-activities.

Another limitation in the present study may be the assessment of the simplified questionnaire. Because of time constraints, the instruments were slightly adjusted, thus making it more difficult to transfer evidence of psychometric properties from previous studies. Despite that Cronbach's alpha values were considered acceptable, this limitation should be considered when drawing conclusions from the study.

One concern relates to the teacher(s) in charge of the lessons. The lead author was actively engaged in the teaching of disc golf, while the participants' regular PEteacher was responsible for the soccer-lesson. Thus, the study was dependent on the teachers' loyalty toward the study-protocol for the soccer-lesson. After each lesson, conversations with the teachers involved were conducted to identify whether the protocol was met or not. However, the fact that the "guest teacher" may have had an effect of its own, may bias the conclusions drawn from this study. Future studies would benefit from involving extra personnel in order to counterbalance the fact that the teacher in charge may actually be equally important as the activity itself.

\section{Conclusion and recommendations}

Findings from this study indicated that including a new and different activity (disc golf) increased perceived competence in students, compared to general PE and traditional activity (soccer). No main intervention-effect was found for intrinsic and 


\section{K. Vernegaard et al.}

extrinsic motivation. However, when investigating the effect of the intervention conditional of relative attitude toward PE, the findings suggested that the individuals with the relatively positive attitude toward PE reduced their intrinsic motivation from general PE to disc golf, whereas the individuals with relatively negative attitude toward PE increased their intrinsic motivation. Thus, caution should be taken when "giving to the poor", because the "the rich" students may consequently suffer.

Because of the relatively limited nature of the present study, further studies need to be conducted before any conclusion can be drawn with regards to the role of lifestyle sports and other untraditional activities in PE. Future research would do well to build upon the present findings, to strengthen our knowledge of what the optimal PE may look like. Other types of sports, in other forms and lengths, and with different methods of data-collection should be investigated. In sum, research in PE should further strive to understand the dynamics of the PE-context, and learn how to put research into practice.

\section{References}

Allen, I. E. \& Seaman, C. A. (2007). Likert scales and data analyses. Quality Progress, 40(7): 64-65.

Bagøien, T. E., Halvari, H., \& Nesheim, H. (2010). Self-determined motivation in physical education and its links to motivation for leisure time physical activity, physical activity, and well-being in general. Perceptual and Motor Skills, 111(2): 407-432.

Bailey, R. (2006). Physical Education and Sport in Schools: A Review of Benefits and Outcomes. Fournal of School Health, 76(8): 397-401.

Biddle, S. \& Armstrong, N. (1992). Children's physical activity: an exploratory study of psychological correlates. Social Science \& Medicine, 34(3): 325-331.

Biddle, S. \& Goudas, M. (1996). Analysis of children's physical activity and its association with adult encouragement and social cognitive variables. Fournal of School Health, 66(2): 75-78.

Bronfenbrenner, U. (1979). The ecology of human development: Experiments by design and nature. Cambridge, MA: Harvard University Press.

Cale, L. (2000). Physical activity promotion in secondary schools. European Physical Education Review 6(1): 71-90.

Chatzisarantis, N. L., Biddle, S. J., \& Meek, G. A. (1997). A self-determination theory approach to the study of intentions and the intention-behaviour relationship in children's physical activity. British fournal of Health Psychology, 2(4): 343-360.

Chatzisarantis, N. L. \& Hagger, M. S. (2009). Effects of an intervention based on self-determination theory on self-reported leisure-time physical activity participation. Psychology and Health, 24(1): 29-48.

Cortina, J. M. (1993). What is coefficient alpha? An examination of theory and applications. Fournal of Applied Psychology, 78(1): 98-104.

Crum, B. J. (1993). Conventional thought and practice in physical education: Problems of teaching and implications for change. Quest, 45(3): 339-356.

Dawes, J. G. (2008). Do data characteristics change according to the number of scale points used? An experiment using 5 point, 7 point and 10 point scales. International fournal of Market Research, 51(1): 61-77.

Deci, E. L. \& Ryan, R. M. (1975). Intrinsic motivation. New York: Plenum Publishing Co.

Deci, E. L. \& Ryan, M. (1985). Intrinsic motivation and self-determination in human behavior. New York: Plenum Publishing Co.

Deci, E. L. \& Ryan, R. M. (2000). The "what" and "why" of goal pursuits: Human needs and the self-determination of behavior. Psychological Inquiry, 11(4): 227-268.

Eichberg, H. (1998). Body Cultures: Essays on Sport, Space E Identity. London: Routledge.

Erdvik, I. B., Øverby, N. C., \& Haugen, T. (2014). Students' self-determined motivation in physical education and intention to be physically active after graduation: The role of perceived competence and identity. Fournal of Physical Education and Sport, 14(2), 232-241. 


\section{Students' motivation in a disc golf-lesson and a soccer-lesson}

Featherstone, M. (1991). Consumer and Postmodernism. London: Sage Publications.

Field, A. P. (2013). Discovering statistics using IBM SPSS statistics: And sex and drugs and rock'n'roll (4th ed.). London: Sage Publications.

Graham, G. (2008). Teaching children physical education: Becoming a master teacher. USA: Human Kinetics.

Green, K., Smith, A., \& Roberts, K. (2005). Young people and lifelong participation in sport and physical activity: a sociological perspective on contemporary physical education programmes in England and Wales. Leisure Studies, 24(1): 27-43.

Guay, F., Vallerand, R. J., \& Blanchard, C. (2000). On the assessment of situational intrinsic and extrinsic motivation: The Situational Motivation Scale (SIMS). Motivation and Emotion, 24(3): 175-213.

Howe, J. (2003). Drawing lines: A report from the extreme world (sic). In: R. Rinehart \& S. Sydnor (eds.). To the extreme: Alternative sports, inside and out, pp. 353-372. Albany, NY: State University of New York Press.

Kimiecik, J. C., Horn, T. S., \& Shurin, C. S. (1996). Relationships among children's beliefs, perceptions of their parents' beliefs, and their moderate-to-vigorous physical activity. Research Quarterly for Exercise E Sport, 67(3): 324-336.

MacPhail, A., Kirk, D. \& Eley, D. (2003). Listening to Young Peopleís Voices: Youth Sports Leaders Advice on Facilitating Participation in Sport. European Physical Education Review, 9(1): 57-73.

Ministeriet for børn, undervisning og ligestilling (2016). EMU homepage. Available at: http://www.emu.dk

Moreno-Murcia, J. A., Huéscar, E. \& Cervelló, E. (2012). Prediction of adolescents doing physical activity after completing secondary education. The Spanish fournal of Psychology, 15(1): 90-100.

Ntoumanis, N. (2001). A self-determination approach to the understanding of motivation in physical education. British fournal of Educational Psychology, 71(2): 225-242.

Pelletier, L. G., Fortier, M. S., Vallerand, R. J. \& Briere, N. M. (2001). Associations among perceived autonomy support, forms of self-regulation, and persistence: A prospective study. Motivation and Emotion, 25(4): 279-306.

Russell, C. J. \& Bobko, P. (1992). Moderated regression analysis and Likert scales: too coarse for comfort. fournal of Applied Psychology, 77(3): 336-342.

Sallis, J. F., Prochaska, J. J. \& Taylor, W. C. (2000). A review of correlates of physical activity of children and adolescents. Medicine \& Science in Sports \& Exercise, 32(5): 963-975.

Sallis, J. F., Simons-Morton, B. G., Stone, E. J., Corbin, C. B., Epstein, L. H., Faucette, N. \& Rowland, T. W. (1992). Determinants of physical activity and interventions in youth. Medicine $\mathcal{E}$ Science in Sports $\mathcal{E}$ Exercise, 24(6, Suppl): 248-257

Shephard, R. J. \& Trudeau, F. (2010). The legacy of physical education: Influences on adult lifestyle. Pediatric Exercise Science, 12(1): 34-50.

Sonstroem, R. J. (1997). Physical self-concept: assessment and external validity. Exercise E Sport Sciences Reviews, 26(1): 133-164.

Standage, M., Duda, J. L. \& Ntoumanis, N. (2003). A model of contextual motivation in physical education: Using constructs from self-determination and achievement goal theories to predict physical activity intentions. Fournal of Educational Psychology, 95(1): 97-110.

Stanley, D. M., Cumming, J., Standage, M. \& Duda, J. L. (2012). Images of exercising: Exploring the links between exercise imagery use, autonomous and controlled motivation to exercise, and exercise intention and behavior. Psychology of Sport E Exercise, 13(2): 133-141.

Säfvenbom, R., Haugen, T., \& Bulie, M. (2015). Attitudes toward and motivation for PE. Who collects the benefits of the subject? Physical Education and Sport Pedagogy, 20(6), 629-646.

Thornton, A. (2004). Anyone can play this game: Ultimate Frisbee, identity and difference. In: B. Wheaton (ed.). Understanding lifestyle sports: Consumption, identity and difference, pp. 175-196. New York: Routledge.

Utdanningsdirektoratet (2016). Curriculum for physical education. Udir Homepage. Available at: http://www. udir.no

Vlachopoulos, S. P. (2008). The basic psychological needs in exercise scale: measurement invariance over gender. Structural Equation Modeling, 15(1): 114-135.

Vlachopoulos, S. P. \& Michailidou, S. (2006). Development and initial validation of a measure of autonomy, competence, and relatedness in exercise: The Basic Psychological Needs in Exercise Scale. Measurement in Physical Education and Exercise Science, 10(3): 179-201.

Wang, C. J. \& Biddle, S. J. (2001). Young people's motivational profiles in physical activity: A cluster analysis. fournal of Sport E Exercise Psychology, 23(1): 1-22.

Weiss, M. R. (2000). Motivating kids in physical activity. Washington, DC: President's Council on Physical Fitness and Sports Research Digest. 


\section{K. Vernegaard et al.}

Weiss, M. R. \& Duncan, S. C. (1992). The relationship between physical competence and peer acceptance in the context of children's sports participation. Fournal of Sport E Exercise Psychology, 14(2): 177-191.

Wheaton, B. (2010). Introducing the consumption and representation of lifestyle sports. Sport in Society, 13(7-8): 1057-1081.

World Flying Disc Federation. (2016). "The Spirit of the Game”. WFDF homepage. Available at: http://www. wfdf.org/sotg/about-sotg. 